Supporting Information for

\title{
Intragranular Fracture Mechanism of Highly Crystalline Lithium Manganese \\ Oxide during Lithium Insertion/Extraction Reactions
}

Kingo Ariyoshi* and Nan Ukumori

Department of Applied Chemistry and Bioengineering, Graduate School of Engineering,

Osaka City University, 3-3-138 Sugimoto, Sumiyoshi-ku, Osaka 558-8585, Japan

*E-mail: ariyoshi@osaka-cu.ac.jp

Single-phase reaction

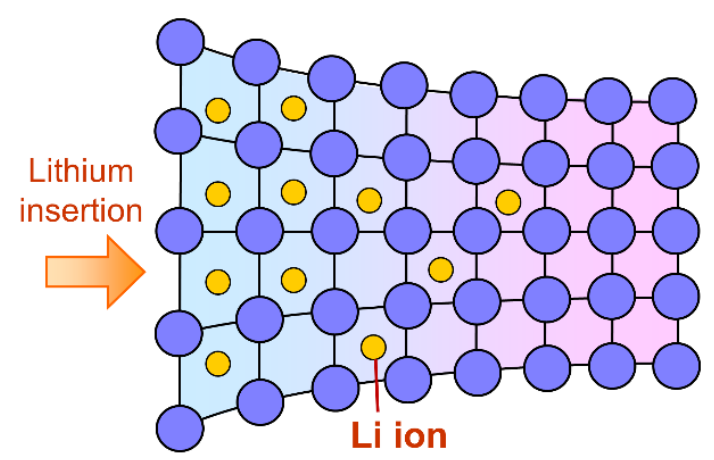

Two-phase reaction

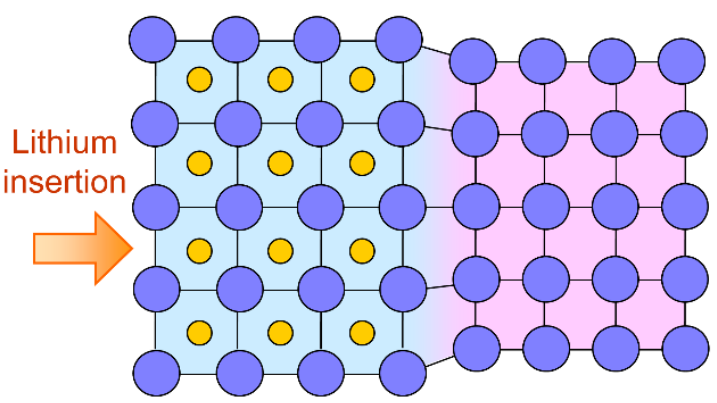

Figure S1. Schematic illustrations of internal stresses generated in lithium insertion materials proceeding along single-phase and two-phase reaction mechanisms. 

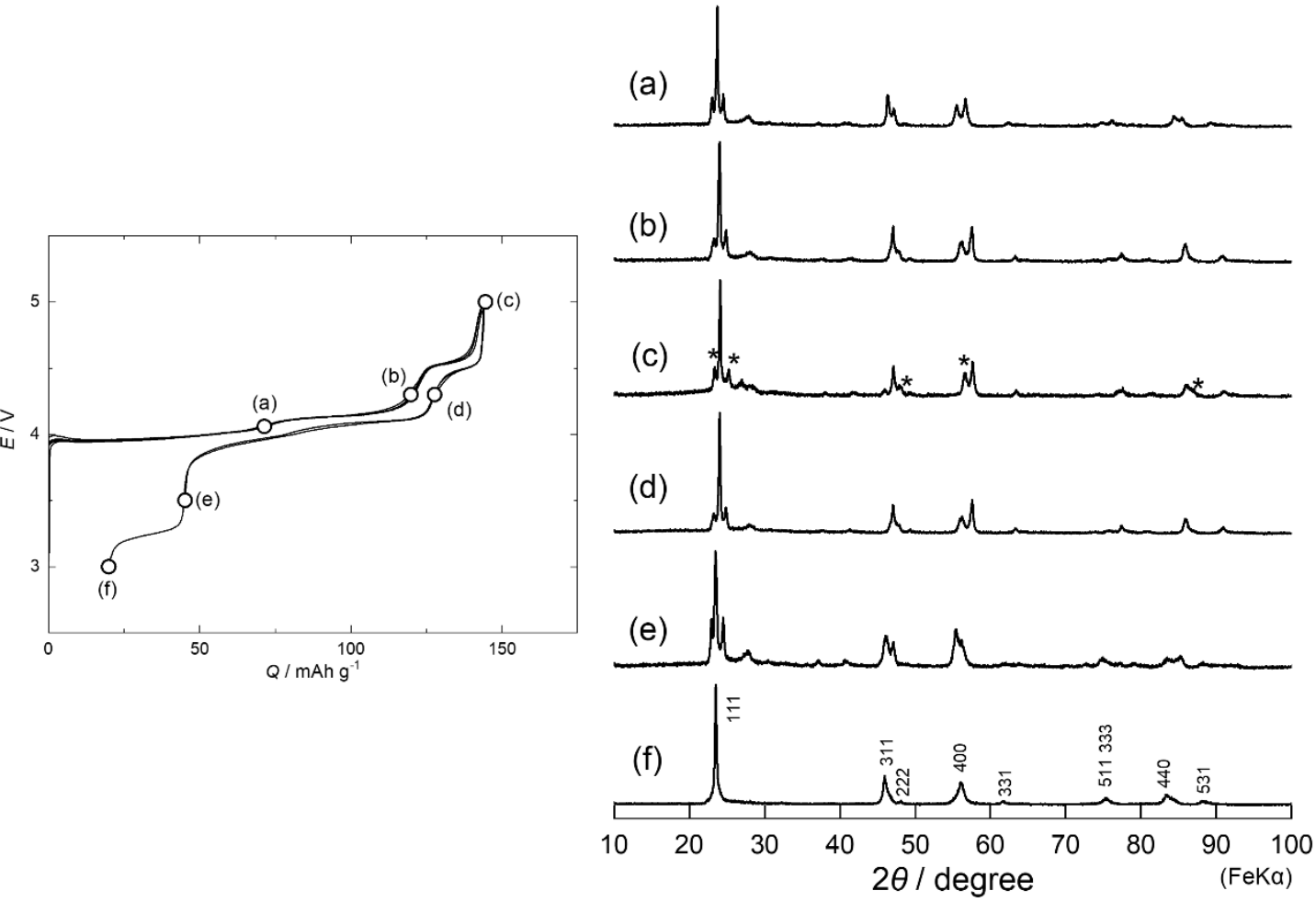

Figure S2. XRD patterns of LMO electrodes during charge and discharge taken at points a-f marked in the charge-discharge curves shown on the left. 

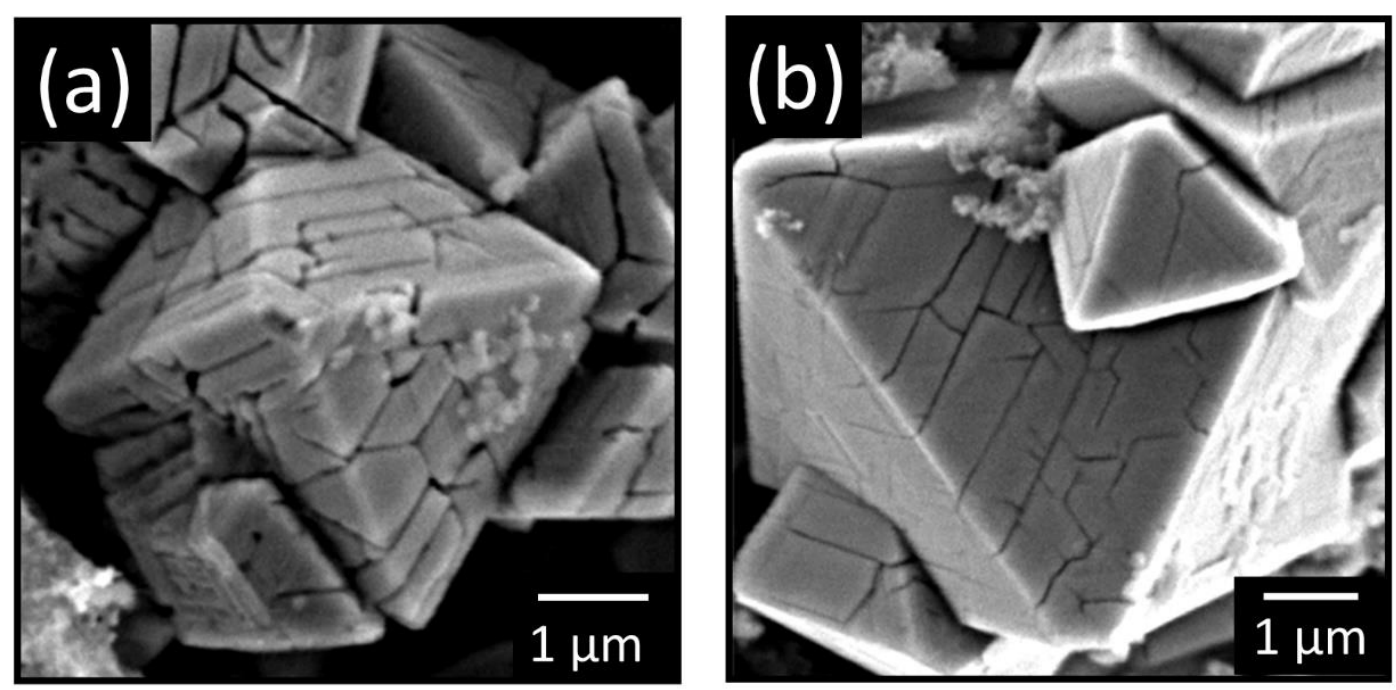

Figure S3. $(a, b)$ SEM images of LMO particles taken following the accelerated cycle test illustrated in Figure 3. 

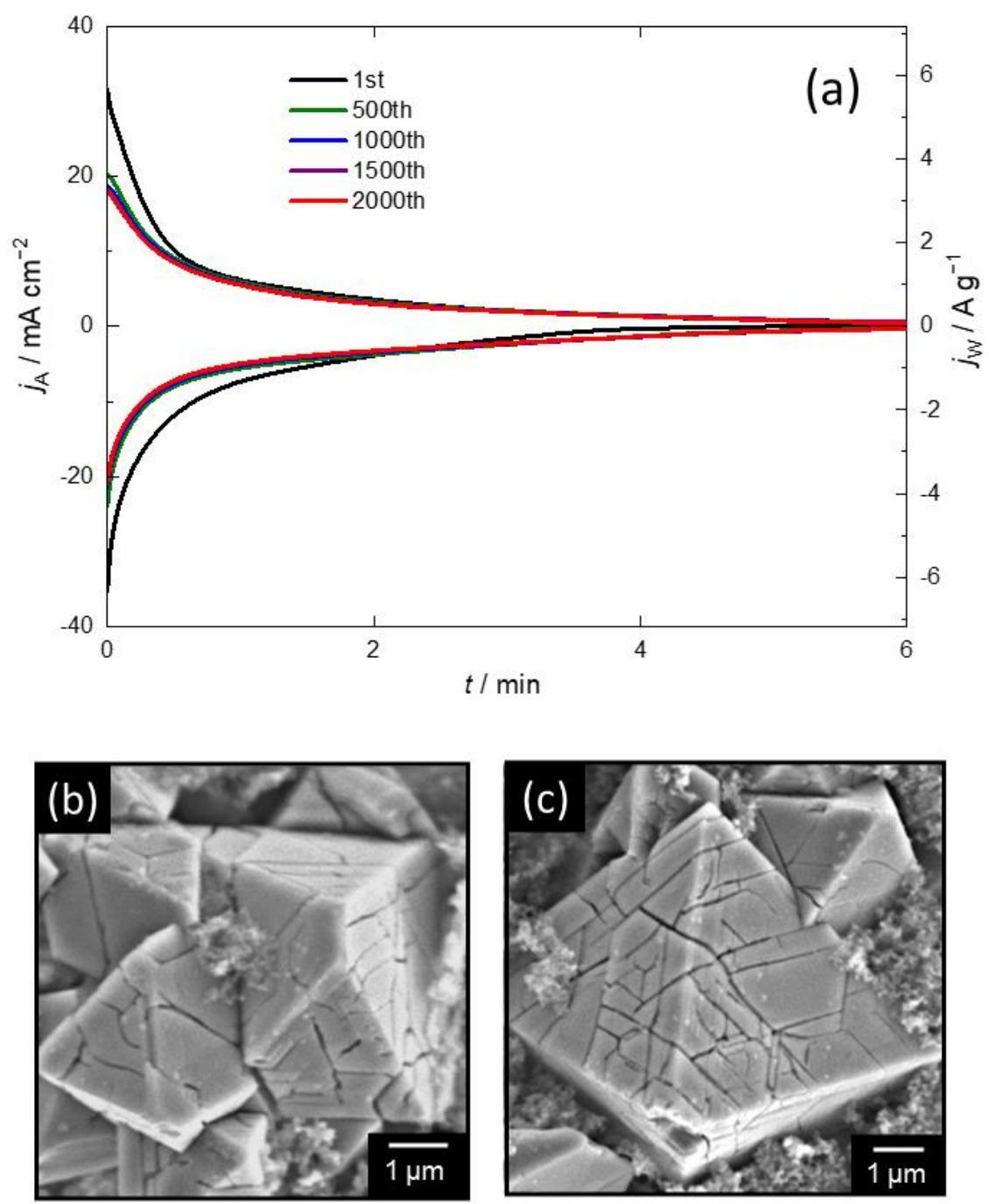

Figure S4. (a) Charge-discharge curves of an $\mathrm{LTO} / \mathrm{Li}\left[\mathrm{Li}_{0.1} \mathrm{Mn}_{1.9}\right] \mathrm{O}_{4}$ cell charged at a constant voltage of $3.5 \mathrm{~V}$ for $6 \mathrm{~min}$ and discharged at $1.5 \mathrm{~V}$ for $6 \mathrm{~min}$. Current decays are shown for the 1st, 500th, 1000th, 1500th, and 2000th cycles. (b, c) SEM images of $\mathrm{Li}\left[\mathrm{Li}_{0.1} \mathrm{Mn}_{1.9}\right] \mathrm{O}_{4}$ particles taken following the accelerated cycle test. 

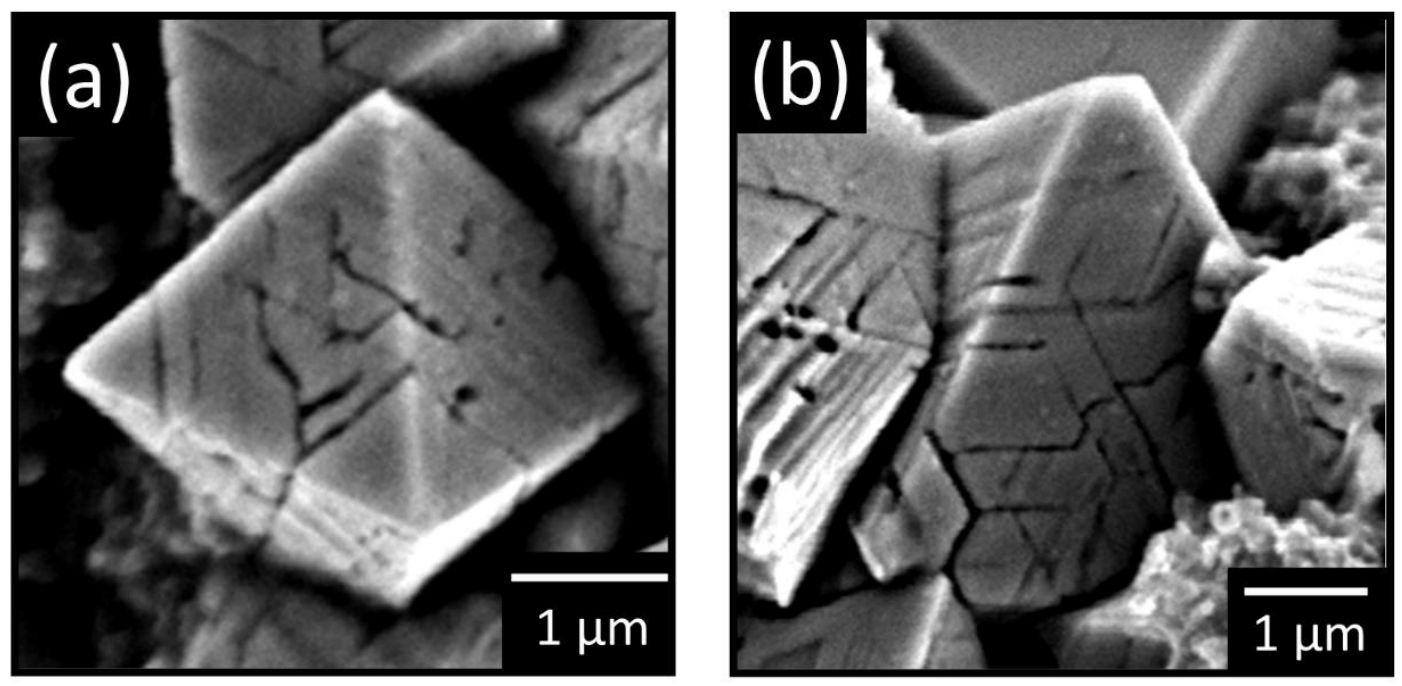

Figure S5. (a, b) SEM images of LMO particles taken following the overcharge test illustrated in Figure 4. 


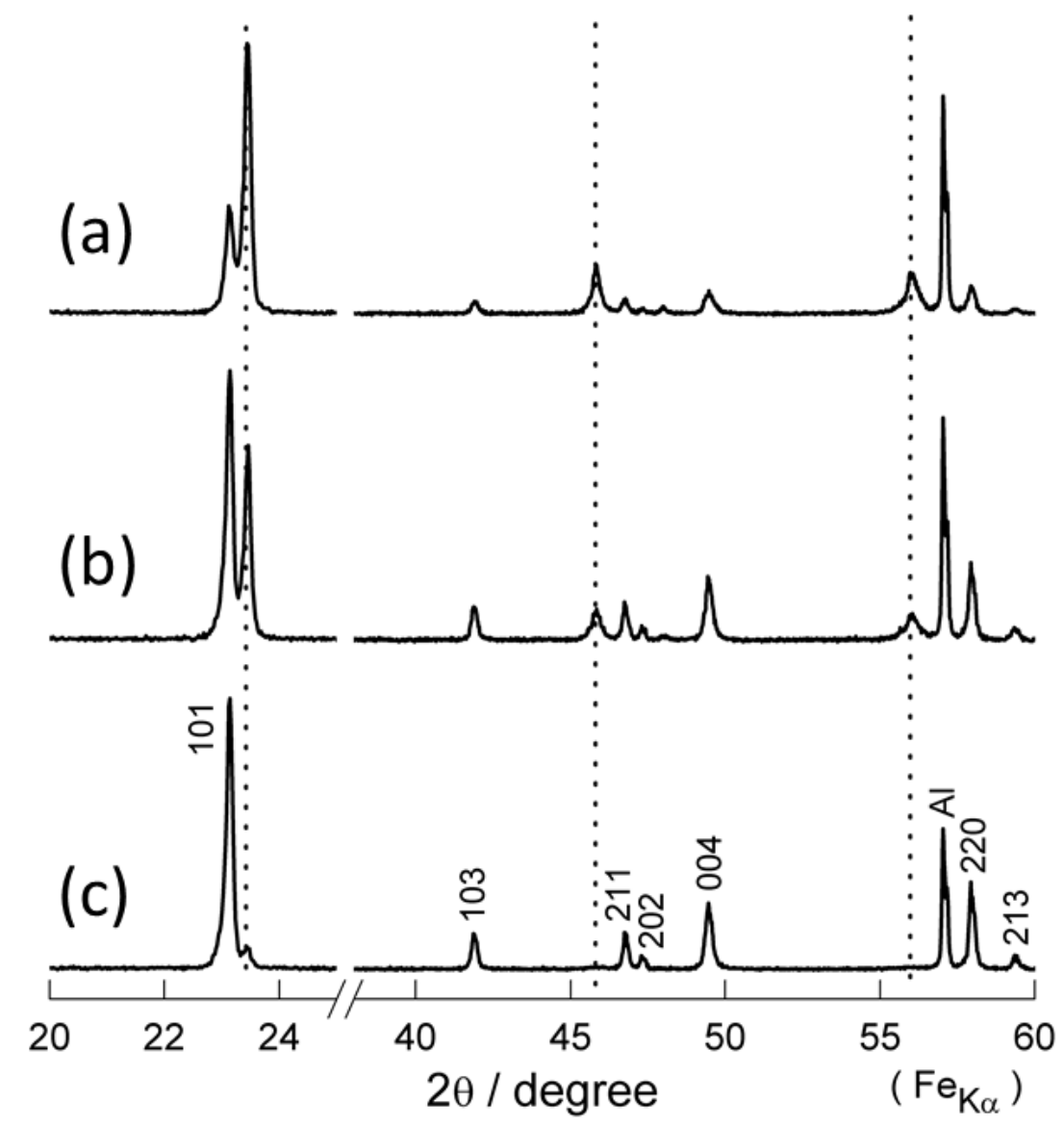

Figure S6. XRD patterns of LMO electrodes discharged to (a) 50, (b) 100, and (c) 140 $\mathrm{mAh} \mathrm{g}^{-1}$. The Miller indices shown in (c) are assigned considering a tetragonal lattice. 

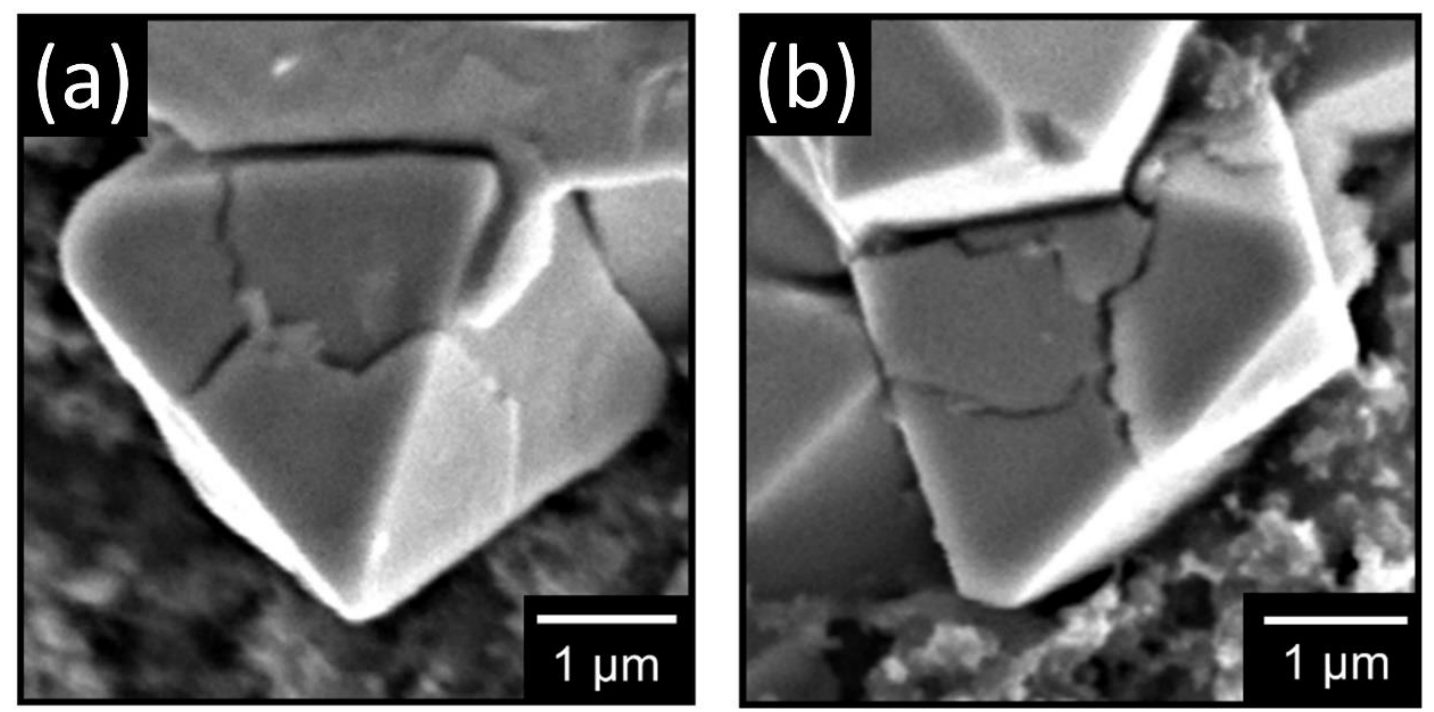

Figure S7. (a, b) SEM images of LMO particles taken following the cycle test in the 3 V region illustrated in Figure 5. 